\title{
OPEN Advantages and limitations of microtiter biofilm assays in the model of antibiofilm activity of Klebsiella phage KP34 and its depolymerase
}

\author{
Agnieszka Latka \& Zuzanna Drulis-Kawa
}

One of the potential antibiofilm strategies is to use lytic phages and phage-derived polysaccharide depolymerases. The idea is to uncover bacteria embedded in the biofilm matrix making them accessible and vulnerable to antibacterials and the immune system. Here we present the antibiofilm efficiency of lytic phage KP34 equipped with virion-associated capsule degrading enzyme (depolymerase) and its recombinant depolymerase KP34p57, depolymerase-non-bearing phage $\mathrm{KP} 15$, and ciprofloxacin, separately and in combination, using a multidrug-resistant $K$. pneumoniae biofilm model. The most effective antibiofilm agents were (1) phage KP34 alone or in combination with ciprofloxacin/phage KP15, and (2) depolymerase KP34p57 with phage KP15 and ciprofloxacin. Secondly, applying the commonly used biofilm microtiter assays: (1) colony count, (2) LIVE/DEAD BacLight Bacterial Viability Kit, and (3) crystal violet (CV) biofilm staining, we unravelled the main advantages and limitations of the above methods in antibiofilm testing. The diverse mode of action of selected antimicrobials strongly influenced obtained results, including a false positive enlargement of biofilm mass (CV staining) while applying polysaccharide degrading agents. We suggest that to get a proper picture of antimicrobials' effectiveness, multiple examination methods should be used and the results must be read considering the principle of each technique and the antibacterial mechanism.

Klebsiella pneumoniae is a rod-shaped, nonmotile, encapsulated, Gram-negative bacillus prevalent in the environment as well as colonizing skin, mucosal tissues, and intestines as an inhabitant of the human microbiome ${ }^{1}$. World Health Organization (WHO) marked this dangerous opportunistic bacterium as a critical priority pathogen, resistant to all or nearly all available antibiotics ${ }^{2,3}$. Klebsiella pneumoniae is a representative of multidrug-resistant ESKAPE group (Enterococcus faecium, Staphylococcus aureus, Klebsiella pneumoniae, Acinetobacter baumannii, Pseudomonas aeruginosa, Enterobacter spp.) being able to infect the immune-compromised people as the nosocomial (hospital-acquired) pathogen, as well as colonize healthy individuals causing the community-acquired infections ${ }^{4}$.

Klebsiella pneumoniae capacity to cause infection and to evade the host immune system is assigned to the capsule (CPS), LPS, membrane transporters, and siderophores ${ }^{5}$. Klebsiella pneumoniae inhabiting both the environment and patients, is surrounded by a thick mucoid mainly acidic capsules, making a shield against desiccation, detergents, antibiotics and the host immune defense system ${ }^{6}$. Klebsiella efficiently forms a biofilm on medical devices like catheters or endotracheal tubes being the main source of nosocomial infections $s^{4,7}$. The wide usage of indwelling medical devices, such as respiratory support equipment and catheters, especially in neonatal wards and in long-term patients, is related to a high prevalence of $K$. pneumoniae infections $s^{9,10}$.

Biofilms are aggregates of bacterial cells embedded in a matrix composed of exopolysaccharides (EPS), extracellular DNA, and proteins ${ }^{11}$. The sessile cells are more resistant to antibiotics compared to planktonic cells ${ }^{12,13}$. The resistance can be physical due to biofilm matrix composition or physiological cell conditions depending on: (1) the metabolic state of bacteria versus antibiotic mode of action, (2) an adaptive tolerance (temporary, nongenetic tolerance due to antibiotic exposition), and (3) active resistance mechanisms such as antibiotic inactivation, antibiotic target modification or efflux pumps overproduction ${ }^{14}$. The nutrients limitation and hypoxia 
a

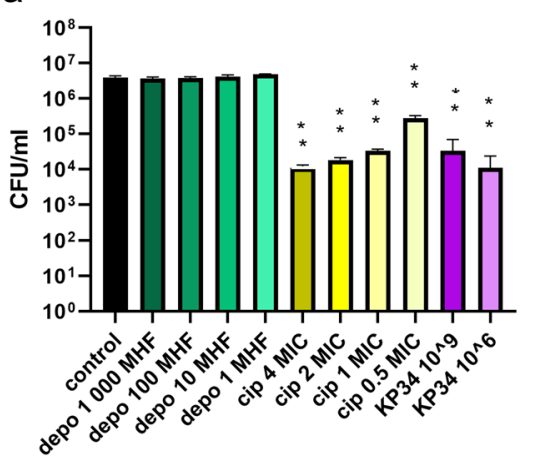

$\mathrm{b} \bar{\varepsilon}$

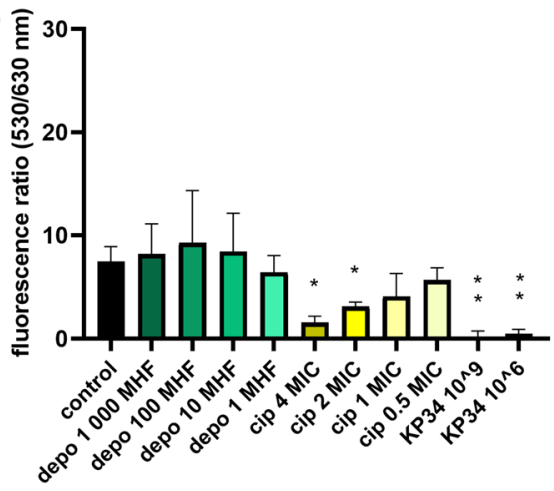

C

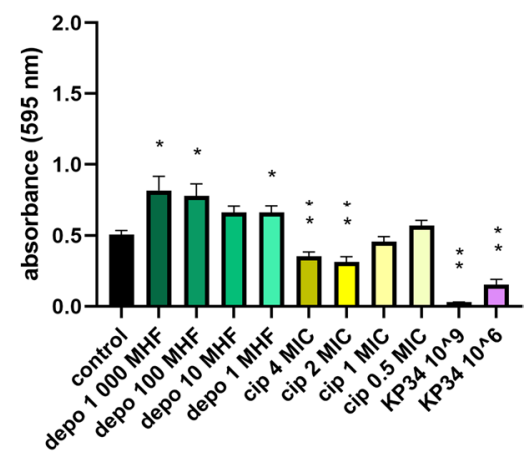

Figure 1. The influence of depolymerase, ciprofloxacin, and infective phage KP34 on K. pneumoniae 77 biofilm formed for $24 \mathrm{~h}$ on polystyrene pegs. One-day biofilm was treated for $2 \mathrm{~h}$ with: recombinant depolymerase KP34p57 originated from phage KP34 marked as depo, at concentrations corresponding to $1000 \mathrm{MHF}$ (minimal halo forming concentration), $100 \mathrm{MHF}, 10 \mathrm{MHF}$, and $1 \mathrm{MHF}$, green bars; ciprofloxacin marked as cip, at concentrations corresponding to $4 \mathrm{MIC}$ (minimal inhibitory concentration), $2 \mathrm{MIC}, 1 \mathrm{MIC}$, and $0.5 \mathrm{MIC}$, yellow bars; and lytic phage KP34 marked as KP34 $\left(10^{9} \mathrm{PFU} / \mathrm{ml}\right.$ and $10^{6} \mathrm{PFU} / \mathrm{ml}$, violet bars). Biofilm eradication was examined with three different microtiter methods: (a) the colony count (CFU/ml); (b) LIVE/DEAD BacLight Bacterial Viability Kit with live to dead cells ratio at fluorescence $530 / 630 \mathrm{~nm}$; (c) the crystal violet staining and the level of absorbance at $595 \mathrm{~nm} . P$-value $<0.001$ indicated as two asterisks, and $P$-value between 0.01 and 0.001 indicated as one asterisk, were considered statistically significant.

conditions in the biofilm center leading to slow cell metabolism thus decreasing the susceptibility to antibiotics. Since the biofilm resistance is based on complex mechanisms, the combination of multiple defensive strategies must be used to efficiently eradicate those bacterial structures.

One of the options is the application of natural bacterial viruses-phages, specifically recognizing and infecting a bacterial cell, propagating inside and causing cell lysis to release its phage progeny ${ }^{15,16}$. Phages do not easily diffuse within the biofilm matrix because of its viscosity, therefore to overcome this obstacle, some phages are equipped with virion-associated depolymerase, enzymes degrading extracellular polysaccharides (CPS, LPS, or EPS ${ }^{17}$. Depolymerases are highly specific enzymes responsible for receptor recognition, binding, and degradation ${ }^{18}$. If not integrated into the virion mainly as tail spikes or tail fibers, depolymerase may occur also in a soluble form to digest polysaccharides helping progeny to escape the infected cell and diffuse freely in the biofilm matrix. Loosening and peeling off the biofilm structure, these phage enzymes can be facilitated as adjuvants providing an access to the sessile cells for other antimicrobials ${ }^{19,20}$.

In this work we utilized three different microtiter assays: (1) the colony count, (2), LIVE/DEAD BacLight Bacterial Viability method, and (3) crystal violet staining, to determine the antibiofilm effect of antimicrobials with a diverse mode of action. Using the multidrug-resistant $K$. pneumoniae model we wanted to present the discrepancies between different biofilm examination methods after the same way of biofilm treatment, unrevealing the advantages and limitations of commonly used assays ${ }^{21,22}$. We were testing the antibiofilm potential of Klebsiella lytic phage KP34, its recombinant KP34p57 capsule degrading depolymerase (non-bactericidal protein, possessing anti-virulent potential), lytic phage KP15 lacking virion-associated depolymerase, and ciprofloxacin (non-bacteriolytic antibiotic, acting on bacterial DNA gyrase) as a single agent and in the combination of multiple components.

\section{Results}

In the anti-biofilm model, we used the multidrug-resistant K. pneumoniae 77 strain producing extended-spectrum beta-lactamases (ESBL) combined with the resistance to aminoglycosides and trimethoprim/sulfamethoxazole. This strain remained susceptible to fluoroquinolones and carbapenems, therefore ciprofloxacin was selected as a model antibiotic for antibiofilm testing. The antibiofilm activity of lytic phage KP34 and its virion-associated depolymerase KP34p57, as a recombinant protein, was evaluated on K. pneumoniae 77 (K63) early (24 h), and maturated biofilms ( $48 \mathrm{~h}$ and $72 \mathrm{~h}$ ). We wanted to verify if the recombinant KP34p57 (called later depolymerase) can effectively degrade the K. pneumoniae 77 biofilm matrix reducing its biomass and releasing bacterial cells embedded inside. The second task was to compare the antibiofilm efficiency of phage-based preparations versus ciprofloxacin, an antibiotic commonly used against multidrug-resistant $K$. pneumoniae strains. The third task was to test if the phage KP15 specific to bacterial protein receptor and non-infecting encapsulated K. pneumoniae 77 can eradicate the biofilm when mixed with phage KP34 or with recombinant KP34p57. Finally, we checked the most efficient antibiofilm composition of selected antibacterials to get a significant reduction of K. pneumoniae 77 mature biofilm. Following ways of treatment were examined with three different microtiter methods to compare their reliability in the biofilm eradiation monitoring.

The untreated biofilm growth. Bacteria embedded in the biofilm structure (control samples) formed for $24 \mathrm{~h}$ reached 6 logs of CFU/ml (Fig. 1a, black bar) and ten times higher level of cells $\left(10^{7}\right)$ after two and three days of development (Fig. 2a and 3a, black bars). The ratio of living/dead bacteria after the first $24 \mathrm{~h}$ achieved 

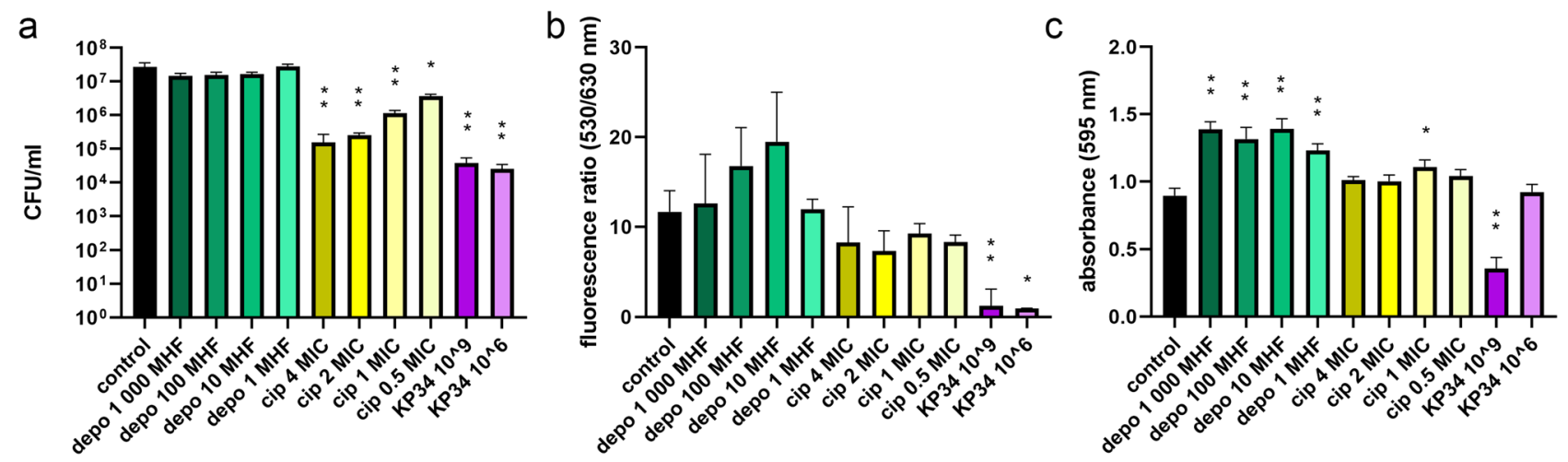

Figure 2. The influence of depolymerase, ciprofloxacin, and infective phage KP34 on K. pneumoniae 77 biofilm formed for $48 \mathrm{~h}$ on polystyrene pegs. Two-day biofilm was treated for $2 \mathrm{~h}$ with: recombinant depolymerase KP34p57 originated from phage KP34 marked as depo, at concentrations corresponding to $1000 \mathrm{MHF}$ (minimal halo forming concentration), $100 \mathrm{MHF}, 10 \mathrm{MHF}$, and $1 \mathrm{MHF}$, green bars; ciprofloxacin marked as cip, at concentrations corresponding to 4 MIC (minimal inhibitory concentration), 2 MIC, 1 MIC, and 0.5 MIC, yellow bars; and lytic phage KP34 marked as KP34 $\left(10^{9} \mathrm{PFU} / \mathrm{ml}\right.$ and $10^{6} \mathrm{PFU} / \mathrm{ml}$, violet bars). Biofilm eradication was examined with three different microtiter methods: (a) the colony count (CFU/ml); (b) LIVE/DEAD BacLight Bacterial Viability Kit with live to dead cells ratio at fluorescence $530 / 630 \mathrm{~nm}$; (c) the crystal violet staining and the level of absorbance at $595 \mathrm{~nm} . P$-value $<0.001$ (indicated as two asterisks) and $P$-value between 0.01 and 0.001 (indicated as one asterisk) were considered statistically significant.
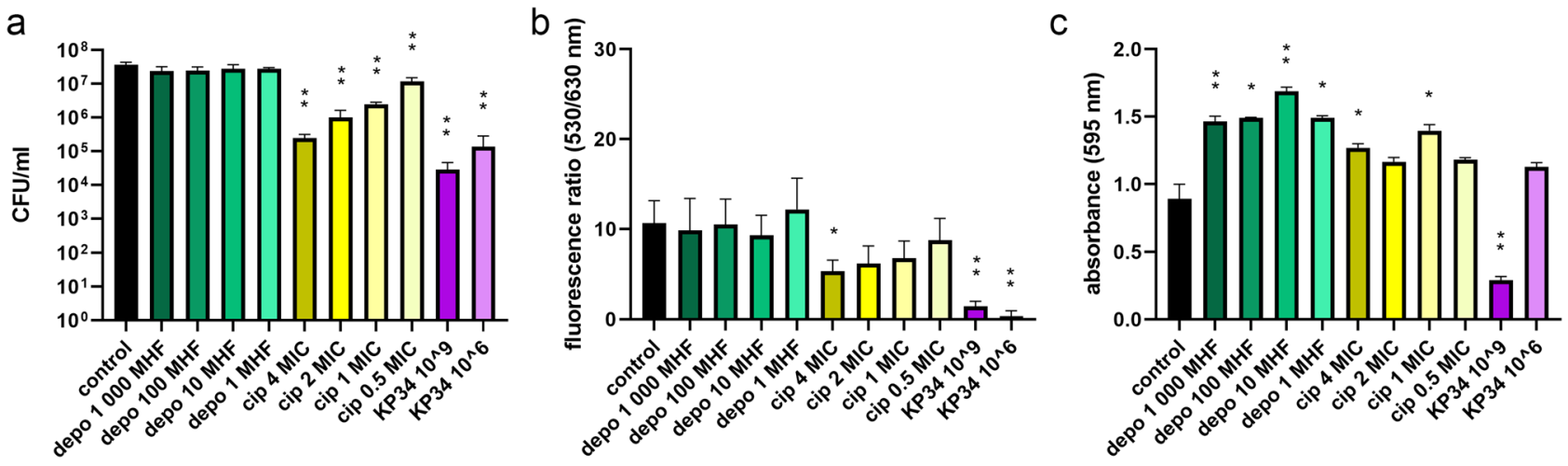

Figure 3. The influence of depolymerase, ciprofloxacin, and infective phage KP34 on K. pneumoniae 77 biofilm formed for $72 \mathrm{~h}$ on polystyrene pegs. Three-day biofilm was treated for $2 \mathrm{~h}$ with: recombinant depolymerase KP34p57 originated from phage KP34 marked as depo, at concentrations corresponding to $1000 \mathrm{MHF}$ (minimal halo forming concentration), $100 \mathrm{MHF}, 10 \mathrm{MHF}$, and $1 \mathrm{MHF}$, green bars; ciprofloxacin marked as cip, at concentrations corresponding to 4 MIC (minimal inhibitory concentration), 2 MIC, 1 MIC, and 0.5 MIC, yellow bars; and lytic phage KP34 marked as KP34 $\left(10^{9} \mathrm{PFU} / \mathrm{ml}\right.$ and $10^{6} \mathrm{PFU} / \mathrm{ml}$, violet bars). Biofilm eradication was examined with three different microtiter methods: (a) the colony count (CFU/ml); (b) LIVE/DEAD BacLight Bacterial Viability Kit with live to dead cells ratio at fluorescence $530 / 630 \mathrm{~nm}$; (c) the crystal violet staining and the level of absorbance at $595 \mathrm{~nm} . P$-value $<0.001$ (indicated as two asterisks) and $P$-value between 0.01 and 0.001 (indicated as one asterisk) were considered statistically significant.

a value of 7.5 and further rose to the level between 10.6 and 11.7 (Figs. 1, 2, 3b, black bars). Similarly, the CV staining showed a gradual increase in biomass during a prolonged biofilm formation and stabilized after $48 \mathrm{~h}$ (Figs. 1, 2, 3c, black bars).

The antibiofilm activity of phage KP34. At the beginning of the study, an antibiofilm activity was determined for each agent separately at the panel of different concentrations or titer (Figs. 1, 2, 3). Lytic phage KP34 activity was tested for two titers $\left(10^{9} \mathrm{PFU} / \mathrm{ml}\right.$ and $\left.10^{6} \mathrm{PFU} / \mathrm{ml}\right)$. The colony count method and live/dead cell kit were recognized as the most effective methods in biofilm eradication monitoring while treated with the phage. It turned out that both phage titers were able to significantly reduce the colony count in the range of 2-3 logs, with the highest reduction (3.1 logs) achieved for $72 \mathrm{~h}$ biofilm treated with $10^{9} \mathrm{PFU} / \mathrm{ml}$ (Figs. 1, 2, 3a, violet bars). Similarly, the live/dead cell ratio was statistically significant reduced $(P$-value $<0.001$, or $0.01-0.001)$ from 86 to $99.7 \%$ for all stages of biofilm formation (Figs. 1, 2, 3b, violet bars). Bacterial cell lysis caused by phage infection led also to biofilm structure exfoliation, while the lysed cells released their DNA ready to be bound with propid- 
ium iodide. It means less number of living cells and more free DNA released from dead cells were responsible for a significant drop in the live/dead ratio. The crystal violet visualized the biofilm biomass reduction of $94 \%, 60 \%$, and $67 \%$ for $24 \mathrm{~h}, 48 \mathrm{~h}$, and $72 \mathrm{~h}$ biofilm, respectively, when a high phage titer was applied (Figs. 1, 2, 3c, violet bars). A lower phage titer $\left(10^{6} \mathrm{PFU} / \mathrm{ml}\right)$ reduced only the $24 \mathrm{~h}$ biofilm $(71 \%)$, whereas no statistically significant influence against older biofilms was seen. Probably the level of phage propagation was too low to cause biofilm exfoliation and partially degraded biomass (negatively charged) interacted with a high number of crystal violet molecules. For further investigation of combined antibiofilm therapy the in-between $10^{8} \mathrm{PFU} / \mathrm{ml}$ phage titer was chosen to observe a possible improved effect of antibacterials combination.

The antibiofilm activity of phage depolymerase. First, the degrading activity of the prepared recombinant enzyme was verified in the serial dilution on a bacterial lawn (spot test), and the extracted K. pneumoniae 77 capsular polysaccharides by zymography assay (Supplementary Materials, Figure S2a, and S1b, respectively). In antibiofilm experiments, four concentrations of KP34p57 depolymerase were tested: $7.5 \mathrm{ng} / \mathrm{ml}$ (corresponding to the minimal concentration of depolymerase able to form transparent halo zone, called further MHFminimal halo forming concentration), $75 \mathrm{ng} / \mathrm{ml}(10 \mathrm{MHF}), 750 \mathrm{ng} / \mathrm{ml}(100 \mathrm{MHF})$ and $7500 \mathrm{ng} / \mathrm{ml}(1000 \mathrm{MHF})$. None of the tested concentrations gave significant changes in the colony count after $2 \mathrm{~h}$ of incubation with the enzyme regardless of the biofilm age (Figs. 1, 2, 3a, green bars). Indeed, the degradation of the bacterial capsule does not lead to cell death. It turned out that 2-h incubation was not enough to release the sessile cells from the biofilm matrix. The application of LIVE/DEAD BacLight Bacterial Viability Kit (Figs. 1, 2, 3b green bars) confirmed that the treatment of $24 \mathrm{~h}$ biofilm with $1 \mathrm{MHF}$ and $72 \mathrm{~h}$ biofilm with $10 \mathrm{MHF}$ concentrations led only to a slight, statistically non-significant live/death ration reduction ( $14 \%$ and $12 \%$, respectively). Depolymerase treatment was not expected to influence the live/dead cells ratio, since it does not cause the cell death or cell membrane damage. These results were consistent with the CFU count method.

On the contrary, the crystal violet staining indicated the biofilm biomass increase after the application of each KP34p57 depolymerase concentration (Figs. 1, 2, 3c, green bars), with the highest range of 164-190\% compared to the control sample. The changes induced by depolymerase treatment of $48 \mathrm{~h}$ - and $72 \mathrm{~h}$ biofilm were statistically significant $(P<0.01)$.

Since there was no significant influence of any tested enzyme concentration on the colony count and live/ dead cells ratio we decided to choose the $10 \mathrm{MHF}$ for further investigation. This concentration had the highest impact on $72 \mathrm{~h}$ - old biofilm (visualized by CV staining) and on the live/dead ratio decrease (however statistically non-significant).

The antibiofilm activity of ciprofloxacin. A bactericidal effect of ciprofloxacin was tested at MICs concentrations established for planktonic K. pneumoniae 77 cells: $4 \mathrm{MIC}=1 \mu \mathrm{g} / \mathrm{ml}, 2 \mathrm{MIC}=0.5 \mu \mathrm{g} / \mathrm{ml}, 1$ $\mathrm{MIC}=0.25 \mu \mathrm{g} / \mathrm{ml}$ and $0.5 \mathrm{MIC}=0.125 \mu \mathrm{g} / \mathrm{ml}$. Each tested concentration resulted in a statistically significant decrease of the colony count after two-hour treatment (Figs. 1, 2, 3a, yellowish bars). The lowest influence was observed for the mature biofilm treated with $0.5 \mathrm{MIC}(0.5 \log$ and $0.9 \log$ reduction for $72 \mathrm{~h}$ and $48 \mathrm{~h}$ biofilm, respectively) and $1.2 \mathrm{log}$ reduction of cells embedded in the early biofilm. An increased antibiotic concentration $(1,2$, and 4 MICs) were more efficient reducing in the colony count between 1 and $2.6 \operatorname{logs}$ (Figs. 1, 2, 3a, yellowish bars).

The SYTO 9/propidium iodide staining indicated 79\%, 29\%, and 50\% reduction of live/dead cells ratio starting from an early to mature biofilm after treatment with $4 \mathrm{MIC}$ of ciprofloxacin (Figs. 1, 2, 3b, yellowish bars). The influence on the early and mature biofilm was statistically significant ( $P$-value between 0.01 and 0.001$)$, while a $48 \mathrm{~h}$ biofilm was not harmed. Lower antibiotic concentrations (0.5-2 MICs) caused non-significant changes (18-45\%). Only 2 MIC of ciprofloxacin significantly reduced (58\%) the live/dead ration of cells embedded in early biofilm. Ciprofloxacin concentration of 4 MIC was chosen for further investigation, as it was effective on the mature biofilm. Live/dead ratio results were not consistent with the data obtained for the colony count method, where each antibiotic concentration had a significant impact on the CFU number. These differences may be based on the ciprofloxacin mode of action, which led to bacterial cell death but not to bacterial cell lysis. In this case, the dead cells are probably not efficiently penetrated by propidium iodide, thus the reduction of live/dead cells ratio was not observed. To confirm that hypothesis, the additional experiment was performed on planktonic cells treated accordingly for $2 \mathrm{~h}$ with $4 \mathrm{MIC}$ of ciprofloxacin and stained with the LIVE/DEAD BacLight Bacterial Viability Kit (Supplementary materials, Fig. S4). The fluorescent microscopy analysis showed the reduced number of living cells compared to untreated control and the elongated shape of bacterial cells after DNA replication blocking caused by ciprofloxacin. Treated cells were both stained with green and red dye but the morphologically changed cells were around 10 times bigger/longer than untreated ones, which may explain the differences in the colony count versus the live/dead ratio.

The CV staining indicated the biofilm eradication only for early biofilm treatment with 4 MIC, 2 MIC, and 1 MIC of ciprofloxacin $(31 \%, 39 \%$, and $10 \%$ of biomass reduction, respectively), and only the changes for 4 MIC and 2 MIC were recognized as statistically significant $(P$-value $<0.001)$. The mature biofilm seemed to be stimulated by antibiotic treatment, having a statistically significant increase of $23 \%$ ( $1 \mathrm{MIC}$ on $48 \mathrm{~h}$ biofilm), as well as of $43 \%$ for 4 MIC and $57 \%$ for 1 MIC against $72 \mathrm{~h}$ biofilm (Figs. 1, 2, 3c, yellowish bars). For further antibiofilm experiments of combined therapy, only the 4 MIC ciprofloxacin concentration was chosen.

The antibiofilm activity of combined preparations. The colony count in the biofilm formed for $48 \mathrm{~h}$ and $72 \mathrm{~h}$ stayed at the same level, therefore only $72 \mathrm{~h}$ mature biofilm was selected for further antibiofilm experiments. For combined antibiofilm treatment the following antimicrobials were used: $10^{8} \mathrm{PFU} / \mathrm{ml}$ of phages, 10 MHF of KP34p57 depolymerase, and 4 MIC of ciprofloxacin (Fig. 4). 
a

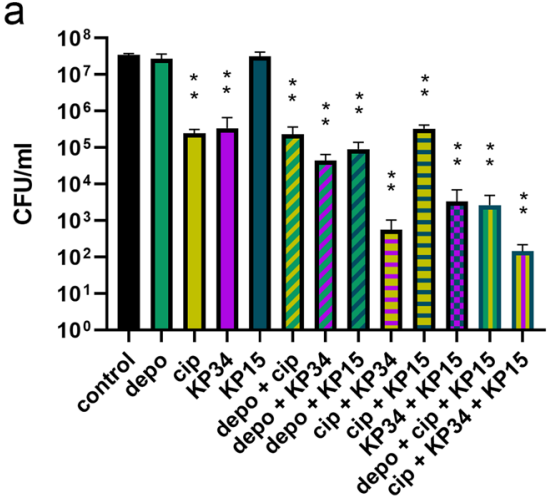

b

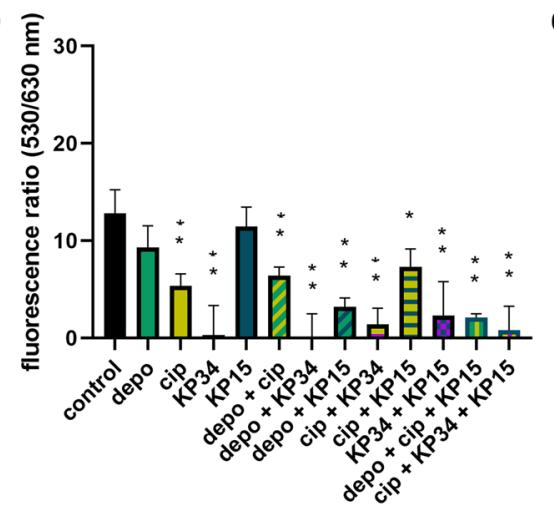

C

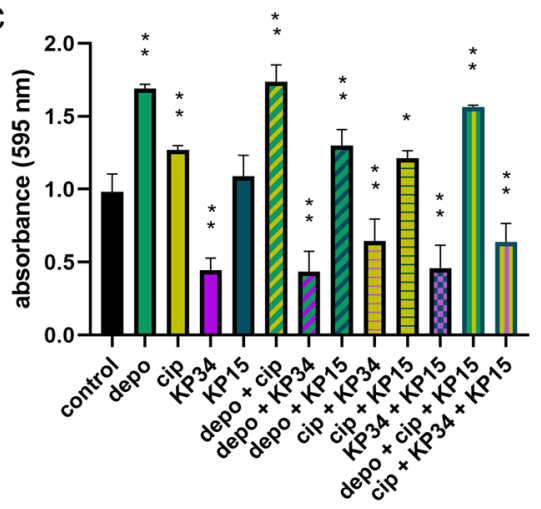

Figure 4. The antibiofilm activity of combined preparations composed of KP34p57 recombinant depolymerase (depo) at concentration corresponding to $10 \mathrm{MHF}$ (minimal halo forming concentration), ciprofloxacin (cip) at concentration corresponding to $4 \mathrm{MIC}$ (minimal inhibitory concentration), lytic phage KP34 specific to K. pneumoniae 77 (KP34, $10^{8} \mathrm{PFU} / \mathrm{ml}$ ), and lytic phage KP15 non-specific to K. pneumoniae 77 (KP15, $10^{8}$ $\mathrm{PFU} / \mathrm{ml}$ ) on K. pneumoniae 77 biofilm formed for $72 \mathrm{~h}$ on polystyrene pegs. The $72 \mathrm{~h}$ biofilm was treated for two hours with different combinations of antimicrobials as indicated under the columns. Plus (+) between abrreviations indicates that two or three antimicrobials were mixed and used simultaneously. Biofilm eradication was examined with three different microtiter methods: (a) the colony count (CFU/ml); (b) LIVE/ DEAD BacLight Bacterial Viability Kit with live to dead cells ratio at fluorescence 530/630 nm; (c) the crystal violet staining and the level of absorbance at $595 \mathrm{~nm}$. $P$-value $<0.001$ (indicated as two asterisks) and $P$-value between 0.01 and 0.001 (indicated as one asterisk) were considered statistically significant.

Depolymerase did not improve nor negatively influenced antibiotic activity, since the combination of both agents (depolymerase plus ciprofloxacin) and ciprofloxacin itself made the same impact on biofilm (2.2 logs of CFU reduction and $50 \%$ in live/dead ratio, $P$-value $<0.001$, Fig. $4 \mathrm{a}, \mathrm{b}$, green/yellowish striped and yellowish bars). On the contrary, CV staining indicated again an increase of biofilm biomass for depolymerase/antibiotic combination and depolymerase treatment itself $(\sim 170 \%$ compared to the control, $P$-value $<0.001$, Fig. $4 \mathrm{c})$.

No significant differences were observed after biofilm treatment with depolymerase and depolymeraseproducing phage KP34 (Fig. 4, green/violet striped and violet bars). In contrast, enzyme combined with phage KP15 allows for phage infection with 2.6 logs reduction in CFU and $75 \%$ in live/dead ratio ( $P$-value $<0.001$, Fig. 4 green/navy blue striped). Depolymerase enabled phage KP15 receptor exposition and followed infection since the phage KP15 receptor is hidden beneath the bacterial capsule. A similar effect was observed when phage KP15 was co-infected with depolymerase-bearing phage KP34.

The most effective antibiofilm combinations were: (1) ciprofloxacin with phage KP34, (2) depolymerase producing phage KP34 together with depolymerase-non-bearing phage KP15, and (3) both phages mixed with an antibiotic. For the aforementioned combinations the biofilm eradication was detected at the level of 4-5.7 logs reduction in the colony count, $82-94 \%$ drop of the live/dead ratio, and between 34 and 53\% biomass decrease, $(P$-value $<0.001$, Fig. 4$)$. Biofilm treatment with a triple cocktail containing depolymerase, depolymerase-nonbearing phage KP15, and ciprofloxacin resulted in a high CFU and live to dead ratio reduction as well (4.1 logs and $83.5 \%$ respectively, $P$-value $<0.001$, Fig. $4 \mathrm{a}$,b, green/yellowish/navy blue vertical striped bar). The CV staining method indicated a significant biomass increase for most of the depolymerase application samples.

\section{Discussion}

In this study, we have two main aims. The first was to determine the activity of a recombinant phage-encoded enzyme (depolymerase KP34p57), lytic phages (producing and non-producing depolymerase), and commonly used antibiotic (ciprofloxacin) in the matter of multidrug-resistant K. pneumoniae biofilm eradication. The second aim was to use the above model to unravel the most common problems regarding inconsistent results obtained in the microtiter antibiofilm assays when determining the activity of different agents including antibiotics, phages, and matrix-degrading enzymes.

The eradication efficiency of $\boldsymbol{K}$. pneumoniae biofilm by different agents. Klebsiella pneumoniae is well protected from chemicals and the host immune system by a thick polysaccharide capsule, and transferring to sessile cells embedded in the biofilm matrix. Phages equipped with depolymerase can use these specific enzymes to degrade matrix structure and gain access to bacteria hidden inside ${ }^{17}$. It was suggested that depending on biofilm topography, phages could travel within through the channels and pores causing further structure exfoliation ${ }^{17}$. Therefore, recombinant depolymerases and phage equipped with virion-associated depolymerase are interesting candidates as antibiofilm agents alone or in combination with other antimicrobials. The antibiofilm potential of phage-borne enzymes was already confirmed in the literature for phage SH-KP152226encoded depolymerase degrading K. pneumoniae biofilm ${ }^{23}$. The biofilm was treated with Dep42 depolymerase at concentrations of 1 or $10 \mu \mathrm{g} / \mathrm{ml}$ reducing the CFU of 0.3 logs. When the biofilm examination was performed with CV staining authors observed $0.4-0.7$ of absorbance reduction. In another study, an enzyme derived from 
phage KPO1K2 (not recombinant) was used to treat K. pneumoniae B5055 biofilm decreasing the colony count of $3.3 \operatorname{logs} s^{24}$. The followed study verified the antibiofilm activity of the aforementioned phage KPO1K2 depolymerase and bacteria-borne (Aeromonas punctate) polysaccharide degrading enzyme against K. pneumoniae B5055 sessile cells. It turned out that bacterial enzyme was slightly more effectively giving an average reduction in the bacterial count of 3.3 logs compared to 2.2 logs observed after phage depolymerase treatment ${ }^{25}$. In our experiments, contrary to the above studies, recombinant depolymerase KP34p57 did not significantly reduce the number of colony count or live/dead cells ratio when applied alone at any concentration for two-hour treatment. Only $72 \mathrm{~h}$ biofilm treated with $75 \mathrm{ng} / \mathrm{ml}$ depolymerase was degraded of around 12-24\% (according to live/dead ratio and colony count, respectively) what was still statistically insignificant. Published results were also contradictory to our crystal violet staining, where we saw a significant increase of the biomass for all tested enzyme concentrations and biofilm age. These discrepancies might be explained by the differences in the degrading activity of applied enzymes and the duration of treatment. Our phage-borne depolymerase KP34p57 could be not enough effective within $2 \mathrm{~h}$ to disrupt the biofilm matrix and release most of the embedded cells contrary to Dep42 or Aeromonas punctate depolymerases ${ }^{25}$. The low efficiency of the enzyme might also be addressed to the differences in the exopolysaccharide composition of the matrix, and CPS ${ }^{17}$. However, we have proved that the combination of depolymerase KP34p57 and phage KP15 was very effective in biofilm eradication reducing the CFU of $2.6 \operatorname{logs}$ and $75 \%$ of live/dead ratio. Therefore, we might conclude that phage enzymes are promising adjuvants to non-depolymerase-producing phages.

In this study, we also tested the activity of ciprofloxacin for Klebsiella biofilm eradication. Antibiotic treatment led to a maximum of 2 logs reduction in the colony count both for early and mature biofilms, however, the efficiency was decreasing along with biofilm age. One of the reasons might be the limited diffusion of antibiotics within the mature matrix, therefore a higher concentration of ciprofloxacin was needed to successful penetration and killing of sessile cells (4 MIC). A similar phenomenon was reported for P. aeruginosa biofilm where ciprofloxacin diffusion within biofilm was reduced due to the drug-matrix components binding ${ }^{26}$. The second reason can be associated with the spatial variation in the physiological feature since bacteria in a slowly growing state are less susceptible to the antibiotic action ${ }^{12}$. That was confirmed for Klebsiella strains biofilm eradication with 10 MIC ciprofloxacin used in another study ${ }^{12}$. Considering the unexpected increase in biofilm mass values detected by CV staining we might suggest that the limited ciprofloxacin penetration led to the impact of subinhibitory concentration of antibiotics in the nearhood of cells, forcing bacterial cells to increased EPS production. That effect was previously reported for a sub-MIC ciprofloxacin concentration applied against $P$. aeruginosa and E. coli resulting in the enhanced matrix synthesis and biofilm formation ${ }^{27}$. Another explanation could be based on the release of cell components to the biofilm matrix increasing the total level of negatively charged moieties reacting with crystal violet molecules.

In the presented study, the depolymerase did not improve ciprofloxacin activity giving the level of eradication corresponding to antibiotic action itself. Verma and co-workers showed also ciprofloxacin/depolymerase combination treatment of 5 days-old K. pneumoniae biofilm, but the improvement was only significant when depolymerase pretreatment was followed by ciprofloxacin application ${ }^{24}$. A similar effect was reported in another study $^{23}$ describing a slightly higher eradication ability of phage enzyme Dep42/polymyxin (6 MIC) cocktail against $K$. pneumoniae. It can rather be concluded that phage depolymerases do not interrupt the activity of antibiotics. In contrast, the combination of gentamicin/phage/phage depolymerase was very effective in the treatment of K. pneumoniae B5055 biofilm ${ }^{25}$. While gentamicin itself did not influence the colony count, the aforementioned mixture with phage and depolymerase led to 4 and 5 logs reduction, respectively, but the older biofilm was less sensitive to the treatment procedure ${ }^{25}$.

Regarding phage-borne capsule depolymerase activity in K. pneumoniae biofilm eradication, we may conclude that it depends on the biofilm-forming abilities of strain, variations in matrix composition as well as dissimilarity in enzymatic efficiency of depolymerase.

The best antibiofilm results were obtained here where lytic phage KP34 was applied, and all three applied monitoring methods were consistently indicating a mature biofilm eradication: 3 logs reduction in the colony count ( $\sim 99.9 \%), 86 \%$ and $67 \%$ reduction of live/dead ratio, and biomass, respectively. Analogous results were reported for lytic phage TSK1 infecting K. pneumoniae biofilm affecting both a high biomass reduction (>95\%) and bacterial load removal up to $90-100 \%{ }^{28}$. The efficiency of phage infection is a decisive factor in biofilm eradication, however, the susceptibility of sessile cells to phage infection is strain- and biofilm age-dependent. The supplementation of lytic phage KP34 with ciprofloxacin significantly improved antibiofilm activity from 2 logs to almost 5 logs of CFU reduction in the mature biofilm, in our study. On the contrary, the combination of ciprofloxacin with phage KPO1K2 had no improving effect ${ }^{29}$. The authors, however, reported that a drug/phage treatment resulted in a decreased rate of antibiotic and phage resistance emergence ${ }^{29}$. The following studies on older biofilms, conducted by this group, revealed that ciprofloxacin itself can reduce the colony count of 2 logs but only up to $96 \mathrm{~h}$ biofilm. The 5-7 days biofilms were not susceptible to antibiotic treatment, whereas were still susceptible to phage infection resulting in 3 logs of CFU reduction ${ }^{24}$. Verma and co-workers compared also the activity of two bacteriophages: producing and non-producing depolymerase but exhibiting a similar potential in planktonic K. pneumoniae cell infection. Phage non-producing depolymerase, in contrary to depolymeraseproducer, was not able to reduce the sessile colony count ${ }^{24}$. Here we combined KP34 and KP15 phages (a depolymerase producing and non-producing, respectively), achieving a high antibiofilm effect with 4 logs reduction in the colony count. Phage KP34 itself caused 2 log-decrease whereas KP15 alone was not able to propagate at all. The phage cocktail activity was further improved by the addition of ciprofloxacin (reaching 5.7 logs reduction). The fact that the simultaneous delivery of depolymerase, antibiotic, and phages does not negatively influence the activity of each compound is highly promising from the therapy point of view. The combination of multiple antimicrobial compounds, apart from improved antibiofilm effect, might also be useful in limiting the resistance emergence ${ }^{29}$. 
The advantages and limitations of different biofilm monitoring assays. The second aim of the study presented here was to determine and compare the usefulness of different microtiter techniques applied commonly for antibiofilm monitoring. Therefore we used three different assays allowing us to evaluate various biofilm features. The first one was the colony count, the second was the live/dead ratio determining method, and the last was CV staining (Fig. 5).

Each method has its pros and cons and focuses on different aspects of complex biofilm structure ${ }^{22}$. The colony count reveals only culturable bacteria meaning that the subpopulation of viable but nonculturable bacteria is not detected ${ }^{30,31}$. What is more, the cell count can be easily underestimated due to the improper detachment of biofilm structure and bacterial cell aggregation. As presented in Fig. 5, the strongest CFU reduction was shown for drug and phage treatment (Fig. 5b,c), but only for the later one, it was also accompanied by biomass reduction.

The LIVE/DEAD BacLight Bacterial Viability Kit, with propidium iodide as a compound ${ }^{32,33}$, has also limitations related to the antimicrobial's mode of action. The dye which is supposed to indicate dead cells can only penetrate and stain DNA when the bacterial cell membrane is damaged. Bacteria not being able to reproduce in a suitable environment should be marked as "dead" according to the common viability criterium, but if the cell membrane stays impermeable it will be scored as "alive" when stained with propidium iodide. In our case, the mature biofilm treated with ciprofloxacin was reduced by 2 logs in the colony count, thus one could expect that a live/dead ratio reduction should be around $99 \%$, while in fact, it was only $50 \%$ (Fig. 5b). Ciprofloxacin, a bactericidal antibiotic belonging to fluoroquinolones, acts on topoisomerase IV and DNA gyrase blocking the replication process and cell division ${ }^{34}$. Theoretically, dead microorganisms lose their capability to maintain their membranes intact, which should enable the penetration of propidium iodide (a component of LIVE/DEAD BacLight Bacterial Viability Kit) into the cell. Our study revealed that the inconsistent results in CFU count versus staining came from the formation of elongated cells halted in the division process by ciprofloxacin, thus the life/ dead ratio remained relatively high compared to untreated culture.

Even if the bacterial cells are killed, the biofilm matrix may not be removed, becoming the starting point for biofilm regrowth, thus the third method we used was crystal violet (CV) staining. The CV as a positively charged stain binds to the negatively charged components like polysaccharides, proteins, or nucleic acids. Any antimicrobial agent causing the increase of negatively charged residues will also enhance the formation of CV complex giving to a false interpretation of biofilm biomass enlargement. In this study, the biomass staining showed the eradication effect only when lytic phage was applied at high MOI (Fig. 5c), whereas in the remaining cases, the biomass seemed to increase. It might be due to the negatively charged polysaccharides overproduction (i.e. as a response to the antibiotic treatment, Fig. 5b) or due to an increase of negatively charged components released from the dead cells and trapped in the matrix, or due to the effect of EPS/CPS enzymatic degradation by phageborne depolymerase (Fig. 5d). Other studies proved the efficiency of depolymerase treatment with crystal violet staining $^{23,35}$, which was opposite to results from our study, where we observed an extensive biomass increase after depolymerase treatment. It must be also stressed that the differences in biomass level might also be due to: (1) discrepancies in biofilm formation rate, (2) biofilm structure and matrix composition, and (3) degrading enzyme efficiency. Moreover, the variability in CV staining results may be due to technical protocol. Also, the methods of biofilm development itself differ among the studies: (1) can be grown for a different period, (2) developed in the wells or on pegs, (3) starting $\mathrm{CFU} / \mathrm{ml}$ may differ, or (4) the growing medium can be exchanged/refreshed or not. It seems that CV staining is a convenient method for biofilm growth monitoring where no antimicrobials are applied, but for antibiofilm tests, this technique must be carefully interpreted taking into account the basis of $\mathrm{CV}$ interactions.

Depending on the chosen methodology for antibiofilm analysis, the results of antimicrobial activity might differ significantly, see Fig. 5, thus it is essential to know the mode of action of the applied agent. To properly analyze the effectiveness of the antimicrobial, the multiple examination microtiter methods should be applied and the results must be verified considering the biological and chemical background of each technique.

\section{Summary}

In conclusion, the most effective antibiofilm combinations were: (1) ciprofloxacin with depolymerase producing phage KP34, (2) depolymerase producing phage KP34 together with depolymerase-non-bearing phage KP15, and (3) both phages mixed with the antibiotic. A triple cocktail containing depolymerase, depolymerase-nonbearing phage KP15, and ciprofloxacin resulted in a high CFU and live/dead ratio reduction as well. Lytic activity of phage KP34 itself and in combination with other antimicrobials possess a satisfactory antibiofilm potential. Depolymerase originated from phage KP34 can be used as a supportive antibiofilm agent for depolymerasenon-bearing phages.

Results acquired from different microtiter biofilm assays may differ depending on the mode of action of a particular antimicrobial. Colony count can be underestimated due to bacterial aggregation or detachment of biofilm structure. Live to dead cells ratio calculated from LIVE/DEAD BacLight Bacterial Viability Kit staining strongly depends on the bacterial membrane integrity. Biofilm biomass monitored with crystal violet can be easily overestimated by the variation in negatively charged components. Thus overall the biofilm eradication assays should be carefully interpreted.

\section{Materials and methods}

Phage propagation. Phages KP34 and KP15 were propagated on the respective hosts being Klebsiella pneumoniae 77 and K. pneumoniae ATCC 700603 for phage KP34 and KP15, respectively. Klebsiella pneumoniae 77 from the collection of the Institute of Genetics and Microbiology, University of Wroclaw, Poland, is a multidrug-resistant strain, producing extended-spectrum beta-lactamases (ESBL) combined with the resistance to aminoglycosides and trimethoprim/sulfamethoxazole. This strain remains susceptible to ciprofloxacin and 
a

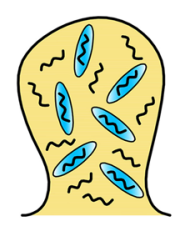

$\mathrm{CFU} / \mathrm{ml}$

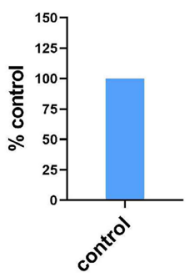

b

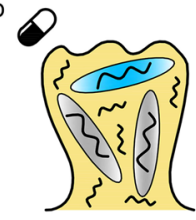

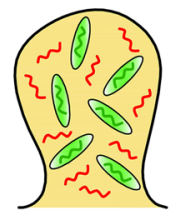
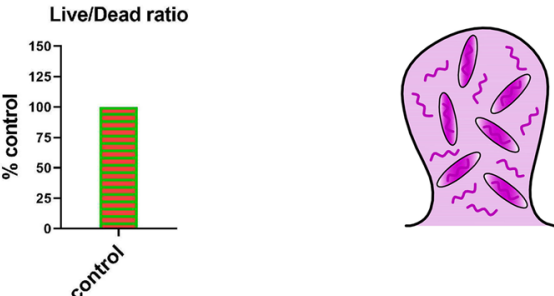

Biofilm biomass
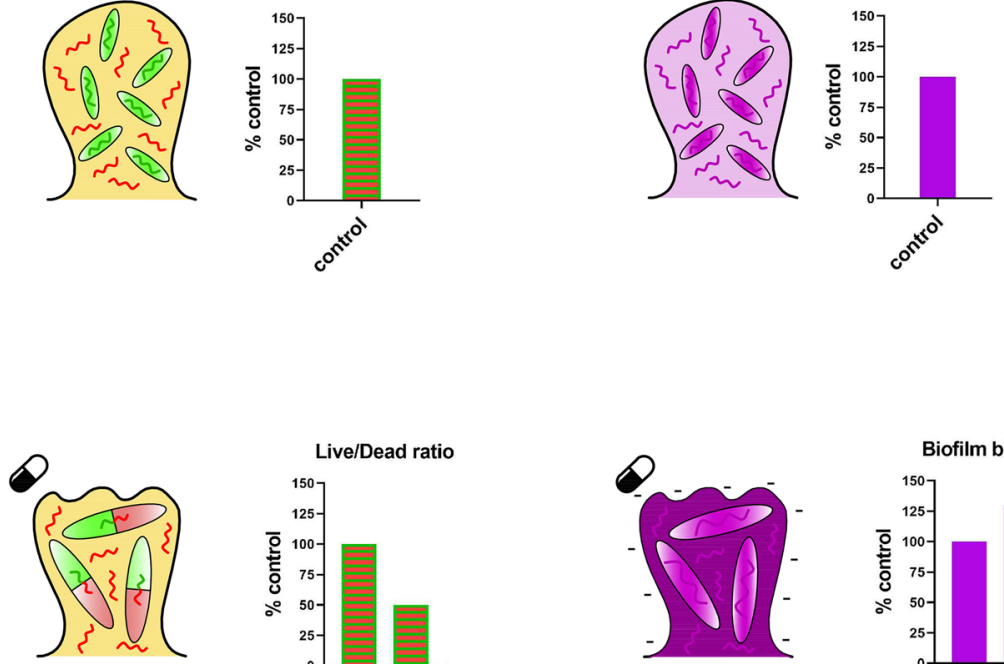

$\mathrm{CFU} / \mathrm{ml}$
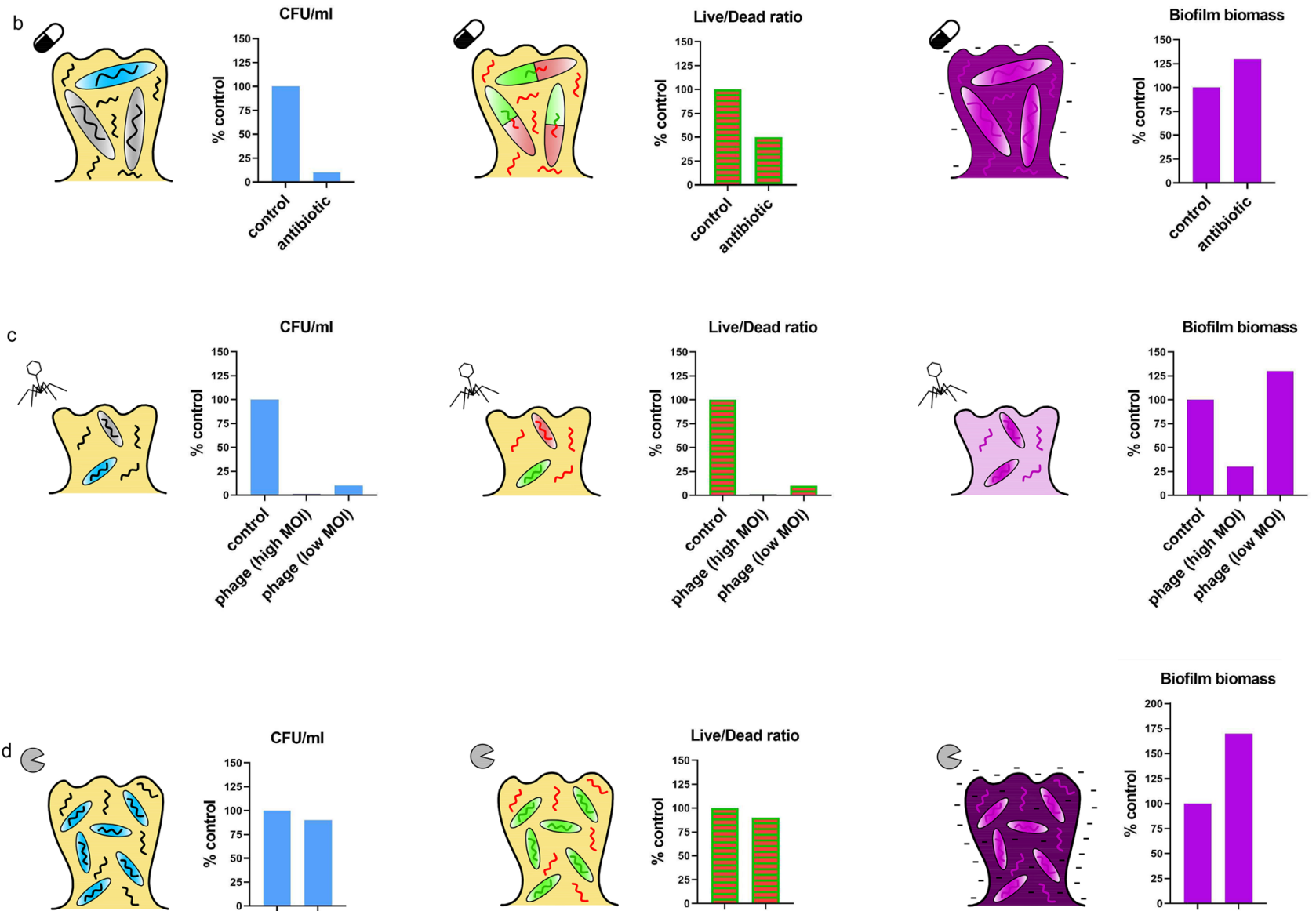
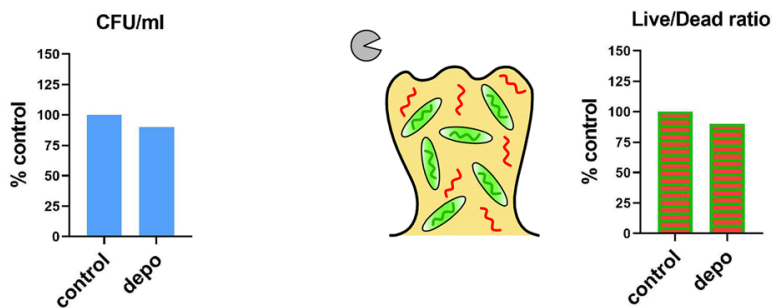

\section{antibiotic}<smiles></smiles>

\section{depolymerase}

३३ईร

DNA

\section{live cell}

dead cell
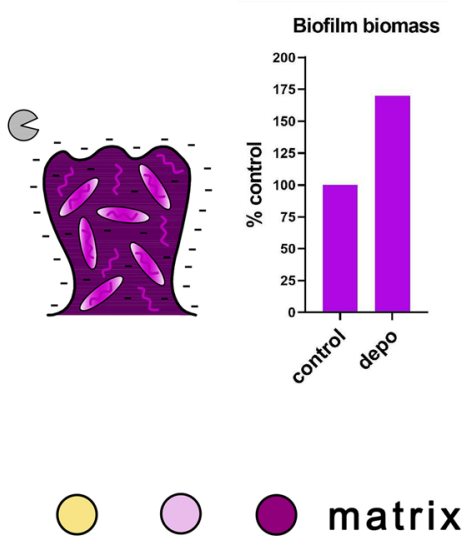

\section{(-) negative charge}

Figure 5. The advantages and limitations of different biofilm monitoring assays used in this study: the colony count (left), LIVE/DEAD BacLight Bacterial Viability Kit (middle), biomass staining with crystal violet (right). The antibiofilm strategies were tested for: (a) untreated biofilm; (b) antibiotic application; (c) phage infection at a high and low MOI; (d) depolymerase action. The colony count indicates only culturable bacteria, thus the antibiotic and phage application showed the best antibiofilm effect. The life/dead ratio gave inconsistent results for ciprofloxacin treatment because of the specific antibiotic mode of action causing the elongation of cells and dyes accumulation. The CV staining is based on the dye interactions with the negative charge thus showed a false enlargement of biofilm after antibiotic, depolymerase, and phage at a low MOI application. 
carbapenems, therefore ciprofloxacin was chosen for antibiofilm testing in this study. The phage lysate at MOI of $0.1-0.01$ was added to $10 \mathrm{ml}$ of a logarithmically growing bacterial culture in Tryptic Soy Broth (bioMerieux, Marcy l'Etoile, France). The incubation at $37^{\circ} \mathrm{C}$ with the agitation was performed for $3 \mathrm{~h}$. The phage lysate was mixed with $0.5 \mathrm{ml}$ of chloroform (VWR, Radnor, Pennsylvania, USA), the top phase was separated and spun down $\left(5000 \times g, 30 \mathrm{~min}, 4^{\circ} \mathrm{C}\right)$. The supernatant was subsequently sterilized by filtration $(0.22 \mu \mathrm{m}$, Merck Millipore, Burlington, Massachusetts, USA). The phage titer was established using the double-agar layer method ${ }^{36}$.

Depolymerase cloning and production. The KP34p57 depolymerase specific to the K63 capsular serotype (YP_003347651.1, locus tag KP34p57) was found to be homologous to pectin lyase (confidence 68,7\%; id 18\%; aa 32-371) by PHYRE2 online tool ${ }^{37,38}$. KP34p57 gene was amplified by PCR using Pfu DNA polymerase (Thermo Fisher Scientific, Waltham, Massachusetts, USA) and the specific primers (F: ATGGCACTCACTAAA CTAGTAGATGCAGG and R: ACCAGTGAGTTCAGATGGAGCAAAGCAGC) and followed by post-amplification 3' A-overhang addition by DreamTaq polymerase (Thermo Fisher Scientific, Waltham, Massachusetts, USA). Subsequently, the amplicons were cloned into the pEXP5-CT/TOPO vector (Invitrogen, Thermo Fisher Scientific, Waltham, Massachusetts, USA) with a C-terminal histidine tag according to the manufacturer's conditions. Transformation of chemocompetent E. coli TOP10 (Invitrogen, Waltham, Massachusetts, USA) for plasmid propagation and isolation was followed by Sanger sequencing (Genomed, Warsaw, Poland) of constructs that were verified by colony PCR as possessing proper construct. Correct constructs were used for E. coli BL21(DE3) transformation and subsequent protein expression.

Escherichia coli BL21(DE3) cells were grown in Luria Broth (Biomaxima, Lublin, Poland) supplemented with ampicillin (TOKU-E, Bellingham, Washington, USA, $100 \mu \mathrm{g} / \mathrm{ml}$ ) at $37^{\circ} \mathrm{C}$ with agitation until $\mathrm{OD}_{600}$ reached $\sim 0.5$ and then induced with $0.1 \mathrm{mM}$ IPTG (isopropyl- $\beta$-D-thiogalactopyranoside (Bio-Connect, Huissen, The Netherlands)), followed by overnight incubation at $20^{\circ} \mathrm{C}$. Cultures were pelleted by centrifugation $(5000 \times g$, $\left.10 \mathrm{~min}, 4^{\circ} \mathrm{C}\right)$ and resuspended in lysis buffer $(0.5 \mathrm{M} \mathrm{NaCl}$ (Acros Organics, Thermo Fisher Scientific, Waltham, Massachusetts, USA), $20 \mathrm{mM} \mathrm{NaH}{ }_{2} \mathrm{PO}_{4}$ (Acros Organics, Waltham, Massachusetts, USA), pH 7.4) and lysed by 3 cycles of freeze-thawing followed by sonication (15-30 s impulse, $30 \mathrm{~s}$ break, 3-5 times, power level 25\%, on ice Bandelin Sonopuls HD 2070). The supernatant fraction was separated from cell debris by centrifugation (30 min, $12,500 \times g, 4^{\circ} \mathrm{C}$ ) and filtered through $0.2 \mu \mathrm{m}$ filter (Merck Millipore, Burlington, Massachusetts, USA) before application on the chromatographic column. For protein purification NGC Medium-Pressure Liquid Chromatography System (Bio-Rad, Hercules, California, USA) combined with Prepacked IMAC Nickel Columns ( $5 \mathrm{ml}$ column volume, Bio-Rad, Hercules, California, USA) and long column wash ( $0.5 \mathrm{M} \mathrm{NaCl}, 20 \mathrm{mM}$ $\mathrm{NaH}_{2} \mathrm{PO}_{4}$, pH 7.4), followed by a wash with buffer supplemented with $25 \mathrm{mM}$ imidazole (Acros Organics, Waltham, Massachusetts, USA) to remove the unspecific binding. The protein was eluted with buffer supplemented with $500 \mathrm{mM}$ imidasole and dialyzed against PBS ( $\mathrm{pH} 7.4$ ) overnight at $4{ }^{\circ} \mathrm{C}$. Purified proteins were kept frozen at $-80^{\circ} \mathrm{C}$ until use.

Minimal Halo Forming (MHF) concentration measurement of depolymerase. The concentration of recombinant depolymerase was measured using the Qubit 2.0 fluorometer (Thermo Fisher Scientific, Waltham, Massachusetts, USA) according to the manufacturer protocol. The depolymerase was serially diluted in Tryptic Soy Broth (TSB, bioMerieux, Marcy l'Etoile, France) to following concentrations: $100 \mu \mathrm{g} / \mathrm{ml}, 10 \mu \mathrm{g} /$ $\mathrm{ml}, 1 \mu \mathrm{g} / \mathrm{ml}$ and further in two-fold dilution series $(500 \mathrm{ng} / \mathrm{ml}, 250 \mathrm{ng} / \mathrm{ml}, 125 \mathrm{ng} / \mathrm{ml}, 62.5 \mathrm{ng} / \mathrm{ml}, 31.25 \mathrm{ng} / \mathrm{ml}$, $15.625 \mathrm{ng} / \mathrm{ml}, 7.8125 \mathrm{ng} / \mathrm{ml}$ and $3.90625 \mathrm{ng} / \mathrm{ml}$ ). Ten $-\mu \mathrm{l}$ drops were spotted on the bacterial lawn to test the halo zone formation. As a control $10 \mu \mathrm{l}$ of PBS and TSB was used (spot assay) ${ }^{39,40}$. Plates were incubated overnight at $37^{\circ} \mathrm{C}$ and checked for the presence of visible opaque areas (halo zones). The MHF concentration was set as the lowest protein concentration at which a halo zone was still visible. The experiments were conducted in triplicate.

Halo forming ability of KP34p57 recombinant depolymerase was presented in Supplementary Materials as Figure S2. In this figure phages, KP34, and KP15 specificity test and depolymerase KP34p57 support for phage KP15 were presented. Figure S2a depicts a spot test on K. pneumoniae 77 bacterial lawn and S2b K. pneumoniae ATCC 700603 bacterial lawn.

Minimal inhibitory concentration (MIC) determination of ciprofloxacin. The MIC of ciprofloxacin (MP Biomedicals, Thermo Fisher Scientific Waltham, Massachusetts, USA) was determined by the broth dilution method according to CLSI (Clinical Laboratory Standards Institute) recommendations. Klebsiella pneumoniae 77 grown on Mueller Hinton Agar (MHA, bioMerieux, Marcy l'Etoile, France) was resuspended in saline to $0.5 \mathrm{McF}$ arland standard (approximately $1.5 \times 10^{8} \mathrm{CFU} / \mathrm{ml}$ ) using a densitometer (bioMerieux, Marcy l'Etoile, France). The serial dilutions of ciprofloxacin stock $(5.1 \mathrm{mg} / \mathrm{ml})$ were prepared in MHB according to CLSI recommendations and pipetted into 96 well plates (twofold dilution series in the range of $256 \mu \mathrm{g} / \mathrm{ml}-0.015 \mu \mathrm{g} /$ $\mathrm{ml})$. Bacteria were added to final $\mathrm{CFU} / \mathrm{ml}$ reaching $5 \times 10^{5}$ and incubated overnight at $37^{\circ} \mathrm{C}$. The absorbance $(600 \mathrm{~nm})$ was measured with Varioscan Lux (Thermo Fisher Scientific, Waltham, Massachusetts, USA). The MIC was established as the lowest concentration inhibiting the visual growth of microorganisms. The experiments were conducted in triplicate.

Biofilm eradication assay. The overnight culture of $K$. pneumoniae 77 in TSB was centrifuged (5 min, $1500 \times g)$. Pelleted cells were washed twice with saline $(0.9 \% \mathrm{NaCl}) .0 .5 \mathrm{McF}$ arland standard corresponding to $1.5 \times 10^{8} \mathrm{CFU} / \mathrm{ml}$ was set in saline using a densitometer (bioMerieux, Marcy l'Etoile, France). The cells were further diluted in TSB and pipetted to 96 well plates. The polystyrene pegs were immersed in wells containing $\sim 10^{6} \mathrm{CFU}$. Biofilm was formed in the humid chamber for $24 \mathrm{~h}, 48 \mathrm{~h}$, and $72 \mathrm{~h}$ at $37^{\circ} \mathrm{C}$ in static conditions. The lid with pegs was transferred to fresh TSB broth every $24 \mathrm{~h}$. After biofilm formation, pegs were washed in saline 
and then transferred to fresh TSB containing different concentrations of depolymerase KP34p57 (1000 MHF, $100 \mathrm{MHF}, 10 \mathrm{MHF}$, and $1 \mathrm{MHF}$ ), ciprofloxacin (MP Biomedicals, Thermo Fisher Scientific Waltham, Massachusetts, USA, 4 MIC, 2 MIC, 1 MIC, and $0.5 \mathrm{MIC})$ and phage KP34 (10 ${ }^{6}$ and $\left.10^{9} \mathrm{PFU} / \mathrm{ml}\right)$. The most optimal concentrations of antibiofilm compounds (10 MHF of depolymerase, $4 \mathrm{MIC}$ of ciprofloxacin, and $10^{8} \mathrm{PFU} / \mathrm{ml}$ ) were chosen for treatments in combinations. The different combinations were tested: depolymerase + antibiotic, depolymerase + phage, antibiotic + phage, depolymerase + phage + antibiotic against developed $72 \mathrm{~h}$ biofilm. Biofilm was treated with antimicrobial agents for $2 \mathrm{~h}$ at $37^{\circ} \mathrm{C}$. Then, pegs were washed twice in saline, and: (a) sonicated for $30 \mathrm{~min}$ in the ultrasonic cleaner with the addition of ice (160 W, Polsonic, SONIC-3, Warsaw, Poland) and serially diluted for colony count; (b) sonicated for $30 \mathrm{~min}$ in the ultrasonic cleaner with the addition of ice (160 W, Polsonic, SONIC-3, Warsaw, Poland) and stained with LIVE/DEAD BacLight Bacterial Viability Kit (Invitrogen, Thermo Fisher Scientific Waltham, Massachusetts, USA) [ ${ }^{41}$, when used in microtiter assay ${ }^{42}$, when used with confocal laser scanning microscopy (CLSM)] in the F-bottom black 96-well plate according to the manufacturer protocol (the fluorescence intensity was measured at a wavelength centered at $530 \mathrm{~nm}$ with the excitation wavelength centered at $485 \mathrm{~nm}$ for live cells and a wavelength centered at $630 \mathrm{~nm}$ with the excitation wavelength centered at $485 \mathrm{~nm}$ for dead cells); (c) stained with $0.01 \%$ crystal violet solution for $15 \mathrm{~min}$ at room temperature and washed with saline for crystal violet assay. The dye was eluted from pegs via 15 min-long incubation in $96 \%$ ethanol and the absorbance was measured at $595 \mathrm{~nm}$ with Varioscan Lux (Thermo Fisher Scientific Waltham, Massachusetts, USA). Biofilm eradication experiments were conducted twice, each condition in five repeats.

The statistical analysis. The statistical analysis was performed using the Brown-Forsythe ANOVA test and Welch's ANOVA test (GraphPad Prism 8). The Dunnett's T3 test was run for multiple comparisons with adjusted $P$-value $<0.001$ (indicated as two asterisks) and $P$ values between 0.01 and 0.001 (indicated as one asterisk). Both $P$ values were considered statistically significant.

Protein visualization with SDS-PAGE. For protein visualization, sodium dodecyl sulfate-polyacrylamide gel electrophoresis (SDS-PAGE, $180 \mathrm{~V}$ for approximately $1 \mathrm{~h}$ ) in $12 \%$ polyacrylamide gels was performed ${ }^{43}$. Protein samples were mixed with five times concentrated reducing sample buffer (Laemmli Sample buffer (BioRad, Hercules, California, USA) supplemented with 2-mercaptoethanol, 5\% v/v) in 1:4 ratio and boiled at $95^{\circ} \mathrm{C}$ for $5 \mathrm{~min}$. Precision Plus Protein Unstained ladder (Bio-Rad, Hercules, California, USA) was used for protein molecular weight (MW) estimation. For protein bands visualization Coomassie brilliant blue R-250 (Bio-Rad, Hercules, California, USA) staining was applied. SDS-PAGE micrograph, as a confirmation of successful overexpression and purification of recombinant depolymerase KP34p57, was added in Supplementary Materials as Figure S1a.

Zymography analysis using extracted and purified exopolysaccharides. The extraction and purification of EPS/CPS were done as described by Bales et al. ${ }^{44}$. Klebsiella pneumoniae 77 biofilm was grown for 5 days at $37^{\circ} \mathrm{C}$ in static conditions. The culture was started by adding $20 \mathrm{ml}$ of overnight K. pneumoniae culture into a flask with a broad bottom and $200 \mathrm{ml}$ TSB (to provide a large surface for biofilm formation). To every $10 \mathrm{ml}$ of biofilm sludge $60 \mu \mathrm{l}$ of formaldehyde was added (to prevent cell lysis) and incubated at RT with shaking for $1 \mathrm{~h}$ followed by the addition of $4 \mathrm{ml}$ of $1 \mathrm{M} \mathrm{NaOH}$ per every $10 \mathrm{ml}$ of sludge. During $3 \mathrm{~h}$-incubation with shaking, the EPS/CPS was extracted. The supernatant containing EPS/CPS was separated by centrifugation $\left(16,800 \times g, 1 \mathrm{~h}, 4^{\circ} \mathrm{C}\right)$ and dialyzed against distilled water $(12-14 \mathrm{kDa}$ molecular weight cut-off membrane, SERVA Electrophoresis GmbH, Heidelberg, Germany) overnight. Trichloroacetic acid (TCA, SERVA Electrophoresis Gmbh, Heidelberg, Germany) was added to the concentration $20 \%$ and incubated on ice for $0.5 \mathrm{~h}$, for proteins and nucleic acids precipitation. To supernatant, separated by centrifugation $\left(16,800 \times g, 1 \mathrm{~h}, 4{ }^{\circ} \mathrm{C}\right), 1.5$ volumes of cold $96 \%$ ethanol (VWR, Radnor, Pennsylvania, USA) was added to precipitate exopolysaccharides from lipids, $24 \mathrm{~h}$ at $-20^{\circ} \mathrm{C}$. EPS/CPS was pelleted by centrifugation $\left(16,800 \times g, 1 \mathrm{~h}, 4{ }^{\circ} \mathrm{C}\right)$, resuspended in ultrapure water, and dialyzed against Milli-Q (12-14 kDa molecular weight cut-off membrane, SERVA Electrophoresis Gmbh, Heidelberg, Germany) overnight. The EPS/CPS solution was lyophilized and resuspended in ultrapure water to desired concentration.

For zymography analysis standard SDS-PAGE gels containing EPS/CPS solution were prepared $(5 \mathrm{mg} / \mathrm{gel})^{45}$. The depolymerase sample was mixed with Laemmli sample buffer in the 1:1 ratio and denatured for 5 min at $95^{\circ} \mathrm{C}$. After SDS-PAGE under standard condition gels were washed three times in ultrapure water $(10 \mathrm{~min}$ with agitation) followed by $48 \mathrm{~h}$-long incubation in renaturation buffer $\left(0.15 \mathrm{M} \mathrm{NaH}_{2} \mathrm{PO}_{4}\right.$ (Acros Organics, Waltham, Massachusetts, USA), 0.010 M MgCl 2 (VWR, Radnor, Pennsylvania, USA); pH 7.0, 0.1\% (v/v) Triton X-100 (SERVA, Heidelberg, Germany)) with gentle agitation. Gels were again washed three times in ultrapure water (10 min with agitation), stained (methylene blue $0.1 \%(\mathrm{w} / \mathrm{v}), 0.001 \%(\mathrm{w} / \mathrm{v}) \mathrm{KOH}$ (VWR, Radnor, Pennsylvania, USA)) for $12 \mathrm{~h}$ and destained in ultrapure water until the opaque bands were visible. Zymography image, as a confirmation of recombinant depolymerase KP34p57 specificity to extracted EPS/CPS from K. pneumoniae 77 culture was added in Supplementary Materials as Figure S1b.

Influence of sonication on K. pneumoniae viability. Klebsiella pneumoniae 77 culture in TSB (bioMerieux, Marcy l'Etoile, France) was diluted to $0.5 \mathrm{McFarland}$ standard (approximately $1.5 \times 10^{8} \mathrm{CFU} / \mathrm{ml}$ ) using a densitometer (bioMerieux, Marcy l'Etoile, France) and sonicated for $30 \mathrm{~min}$ in the ultrasonic cleaner with the addition of ice (160 W, Polsonic, SONIC-3, Warsaw, Poland) and serially diluted for colony count or kept on ice for $30 \mathrm{~min}$ and serially diluted for colony count, as a control. Dilution series were spotted on TSA (bioMerieux, Marcy l'Etoile, France) and after overnight incubation at $37^{\circ} \mathrm{C}$ colonies were counted to calculate CFU. The 
experiment was conducted in four repeats. The comparison of CFU/ml after and without sonication procedure can be found in Supplementary Materials as Figure S3.

Ciprofloxacin activity on planktonic cells verified by LIVE/DEAD BacLight Bacterial Viability Kit and fluorescence microscopy. Klebsiella pneumoniae 77 culture in TSB (bioMerieux, Marcy l'Etoile, France) was diluted to $0.5 \mathrm{McF}$ arland standard, using a densitometer (bioMerieux, Marcy l'Etoile, France) and treated for $2 \mathrm{~h}$ with ciprofloxacin (MP Biomedicals, Thermo Fisher Scientific Waltham, Massachusetts, USA, a final concentration of $1 \mu \mathrm{g} / \mathrm{ml}$, corresponding to $4 \mathrm{MIC}$ for $K$. pneumoniae 77$)$. After this time cultures were centrifuged ( $5 \mathrm{~min}, 1500 \times g)$, pelleted cells were resuspended in the original volume of saline $(0.9 \% \mathrm{NaCl})$ and stained with LIVE/DEAD BacLight Bacterial Viability Kit (Invitrogen, Thermo Fisher Scientific Waltham, Massachusetts, USA) according to the manufacturer protocol. Briefly, $6 \mu$ of SYTO 9 was mixed with $6 \mu$ of propidium iodide and added to $2 \mathrm{ml}$ of filter-sterilized Gibco Distilled Water (Thermo Fisher Scientific Waltham, Massachusetts, USA) and used for 1:1 (v:v) dilutions with the bacterial suspensions. After 15 min incubation in the darkness, suspensions were five times concentrated via pelleting and resuspending in one-fifth volume of saline. Ten $\mu$ d drop was used for visualization with Axio Imager M1 upright wide-field fluorescence microscope (Carl Zeiss, Germany; an illuminator Zeiss HBO 100; a $100 \times$ oil immersion objective Zeiss Plan-Neofluar $100 \times / 1.30$ ). Exposure times were $50 \mathrm{~ms}$. Filter sets were FITC (for SYTO 9) and Texas Red (for propidium iodide). Pictures were taken with Zeiss AxioCam MRC digital color camera combined with Zeiss AxioVision 4.5 software. Pictures taken as the confirmation that LIVE/DEAD BacLight Bacterial Viability Kit can be used for the differentiation between live and dead cells after ciprofloxacin treatment have been added in Supplementary Materials as Figure S4. The antibacterial activity of ciprofloxacin was also confirmed with the colony count.

Received: 3 July 2020; Accepted: 5 November 2020

Published online: 23 November 2020

\section{References}

1. Podschun, R. \& Ullmann, U. Klebsiella spp. as nosocomial pathogens: epidemiology, taxonomy, typing methods, and pathogenicity factors. Clin. Microbiol. Rev. 11, 589-603 (1998).

2. Calfee, D. P. Recent advances in the understanding and management of Klebsiella pneumoniae. F1000Res 6, 1760 (2017).

3. Tacconelli, E. et al. WHO pathogens priority list working group. Discovery, research, and development of new antibiotics: the WHO priority list of antibiotic-resistant bacteria and tuberculosis. Lancet Infect. Dis. 18, 318-327 (2018).

4. Paczosa, M. K. \& Mecsas, J. Klebsiella pneumoniae: going on the offense with a strong defense. Microbiol. Mol. Biol. Rev. 80, 629-661 (2016).

5. Clegg, S. \& Murphy, C. N. Epidemiology and virulence of Klebsiella pneumoniae. Microbiol. Spectr. 4, UTI-0005-2012 (2016).

6. Struve, C. \& Krogfelt, K. A. Pathogenic potential of environmental Klebsiella pneumoniae isolates. Environ. Microbiol. 6, 584-590 (2004).

7. Jagnow, J. \& Clegg, S. Klebsiella pneumoniae MrkD-mediated biofilm formation on extracellular matrix- and collagen-coated surfaces. Microbiology 149, 2397-2405 (2003).

8. Bandeira, M., Carvalho, P. A., Duarte, A. \& Jordao, L. Exploring dangerous connections between Klebsiella pneumoniae biofilms and healthcare-associated infections. Pathogens 3, 720-731 (2014).

9. Ronald, A. The etiology of urinary tract infection: traditional and emerging pathogens. Dis. Mon. 49, 71-82 (2003).

10. Singhai, M., Malik, A., Shahid, M., Malik, M. A. \& Goyal, R. A study on device-related infections with special reference to biofilm production and antibiotic resistance. J. Glob. Infect. Dis. 4, 193-198 (2012).

11. Ribeiro, S. M., Cardoso, M. H., Cândido, Ed. S. \& Franco, O. L. Understanding, preventing and eradicating Klebsiella pneumoniae biofilms. Future Microbiol. 11, 527-538 (2016).

12. Anderl, J. N., Franklin, M. J. \& Stewart, P. S. Role of antibiotic penetration limitation in Klebsiella pneumoniae biofilm resistance to ampicillin and ciprofloxacin. Antimicrob. Agents Chemother. 44, 1818-1824 (2000).

13. Van Laar, T. A., Chen, T., You, T. \& Leung, K. P. Sublethal concentrations of carbapenems alter cell morphology and genomic expression of Klebsiella pneumoniae biofilms. Antimicrob. Agents Chemother. 59, 1707-1717 (2015).

14. Bjarnsholt, T., Ciofu, O., Molin, S., Givskov, M. \& Høiby, N. Applying insights from biofilm biology to drug development-can a new approach be developed?. Nat. Rev. Drug Discov. 12, 791-808 (2013).

15. Weinbauer, M. G. Ecology of prokaryotic viruses. FEMS Microbiol. Rev. 28, 127-181 (2004).

16. Olszak, T., Latka, A., Roszniowski, B., Valvano, M. A. \& Drulis-Kawa, Z. Phage life cycles behind bacterial biodiversity. Curr. Med. Chem. 24, 3987-4001 (2017).

17. Hughes, K. A., Sutherland, I. W. \& Jones, M. V. Biofilm susceptibility to bacteriophage attack: the role of phage-borne polysaccharide depolymerase. Microbiology 144, 3039-3047 (1998).

18. Latka, A., Maciejewska, B., Majkowska-Skrobek, G., Briers, Y. \& Drulis-Kawa, Z. Bacteriophage-encoded virion-associated enzymes to overcome the carbohydrate barriers during the infection process. Appl. Microbiol. Biotechnol. 101, 3103-3119 (2017).

19. Drulis-Kawa, Z., Majkowska-Skrobek, G., Maciejewska, B., Delattre, A. S. \& Lavigne, R. Learning from bacteriophages-advantages and limitations of phage and phage-encoded protein applications. Curr. Protein Pept. Sci. 13, 699-722 (2012).

20. Maciejewska, B., Olszak, T. \& Drulis-Kawa, Z. Applications of bacteriophages versus phage enzymes to combat and cure bacterial infections: an ambitious and also a realistic application?. Appl. Microbiol. Biotechnol. 102, 2563-2581 (2018).

21. Coenye, T. \& Nelis, H. J. In vitro and in vivo model systems to study microbial biofilm formation. J. Microbiol. Methods. 83, 89-105 (2010).

22. Azeredo, J. et al. Critical review on biofilm methods. Crit. Rev. Microbiol. 43, 313-351 (2017).

23. Wu, Y. et al. A novel polysaccharide depolymerase encoded by the phage SH-KP152226 confers specific activity against multidrugresistant Klebsiella pneumoniae via biofilm degradation. Front. Microbiol. 10, 2768 (2019).

24. Verma, V., Harjai, K. \& Chhibber, S. Structural changes induced by a lytic bacteriophage make ciprofloxacin effective against older biofilm of Klebsiella pneumoniae. Biofouling 26, 729-737 (2010).

25. Bansal, S., Harjai, K. \& Chhibber, S. Aeromonas punctata derived depolymerase improves susceptibility of Klebsiella pneumoniae biofilm to gentamicin. BMC Microbiol. 15, 119 (2015).

26. Suci, P. A., Mittelman, M. W., Yu, F. P. \& Geesey, G. G. Investigation of ciprofloxacin penetration into Pseudomonas aeruginosa biofilms. Antimicrob. Agents Chemother. 38, 2125-2133 (1994). 
27. Hoffman, L. R. et al. Aminoglycoside antibiotics induce bacterial biofilm formation. Nature 436, 1171-1175 (2005).

28. Tabassum, R. et al. Complete genome analysis of a Siphoviridae phage TSK1 showing biofilm removal potential against Klebsiella pneumoniae. Sci. Rep. 8, 17904 (2018).

29. Verma, V., Harjai, K. \& Chhibber, S. Restricting ciprofloxacin-induced resistant variant formation in biofilm of Klebsiella pneumoniae B5055 by complementary bacteriophage treatment. J. Antimicrob. Chemother. 64, 1212-1218 (2009).

30. Li, L., Mendis, N., Trigui, H., Oliver, J. D. \& Faucher, S. P. The importance of the viable but non-culturable state in human bacterial pathogens. Front. Microbiol. 5, 258 (2014).

31. Montanez-Izquierdo, V. Y., Salas-Vazquez, D. I. \& Rodriguez-Jerez, J. J. Use of epifluorescence microscopy to assess the effectiveness of phage P100 in controlling Listeria monocytogenes biofilms on stainless steel surfaces. Food Control 23, 470-477 (2012).

32. Cerca, F. et al. SYBR green as a fluorescent probe to evaluate the biofilm physiological state of Staphylococcus epidermidis, using flow cytometry. Can. J. Microbiol. 57, 850-856 (2011).

33. Oliveira, F., Lima, C. A., Brás, S., França, Â. \& Cerca, N. Evidence for inter- and intraspecies biofilm formation variability among a small group of coagulase-negative staphylococci. FEMS Microbiol. Lett. 362, fnv175 (2015).

34. Hooper, D. C. Emerging mechanisms of fluoroquinolone resistance. Emerg. Infect. Dis. 7, 337-341 (2001).

35. Mi, L. et al. Identification of a lytic Pseudomonas aeruginosa phage depolymerase and its anti-biofilm effect and bactericidal contribution to serum. Virus Genes 55, 394-405 (2019).

36. Adams, M. H. In Bacteriophages (ed. Adams, M. H.) 27-30 (Interscience Publishers, Geneva, 1959).

37. Kelley, L. A., Mezulis, S., Yates, C. M., Wass, M. N. \& Sternberg, M. J. E. The Phyre2 web portal for protein modelling, prediction and analysis. Nat. Protoc. 10, 845-858 (2015).

38. Latka, A., Leiman, P. G., Drulis-Kawa, Z. \& Briers, Y. Modeling the architecture of depolymerase-containing receptor binding proteins in Klebsiella phages. Front. Microbiol. 10, 2649 (2019).

39. Adams, M. H. \& Park, B. H. An enzyme produced by a phage-host cell system. II. The properties of the polysaccharide depolymerase. Virology 2, 719-736 (1956)

40. Kutter, E. Phage host range and efficiency of plating. Methods Mol. Biol. 501, 141-149 (2009).

41. Hoerr, V., Ziebuhr, W., Kozitskaya, S., Katzowitsch, E. \& Holzgrabe, U. Laser-induced fluorescence-capillary electrophoresis and fluorescence microplate reader measurement: two methods to quantify the effect of antibiotics. Anal. Chem. 79, 7510-7518 (2007).

42. Muñoz-Egea, M. C., García-Pedrazuela, M., Mahillo, I. \& Esteban, J. Effect of ciprofloxacin in the ultrastructure and development of biofilms formed by rapidly growing mycobacteria. BMC Microbiol. 15, 18 (2015).

43. Laemmli, U. K. Cleavage of structural proteins during the assembly of the head of bacteriophage T4. Nature 227, 680-685 (1970).

44. Bales, P. M., Renke, E. M., May, S. L., Shen, Y. \& Nelson, D. C. Purification and characterization of biofilm-associated EPS exopolysaccharides from ESKAPE organisms and other pathogens. PLoS ONE 8, e67950 (2013).

45. Majkowska-Skrobek, G. et al. Capsule-targeting depolymerase, derived from Klebsiella KP36 phage, as a tool for the development of anti-virulent strategy. Viruses 8, 324 (2016).

\section{Acknowledgements}

Special thanks to Bartlomiej Latka for the graphical support and Mateusz Speruda for help with fluorescence microscope images preparations.

\section{Author contributions}

A.L. Data curation, Formal analysis, Funding acquisition, Investigation, Visualization, Writing-original draft; Z.D.K. Conceptualization, Data curation, Formal analysis, Funding acquisition, Investigation, Writing-review \& editing.

\section{Funding}

The research reported in this publication was supported by the National Science Centre, Poland [Grants Numbers UMO-2015/19/N/NZ1/00014 and UMO-2017/26/M/NZ1/00233].

\section{Competing interests}

The authors declare no competing interests.

\section{Additional information}

Supplementary information is available for this paper at https://doi.org/10.1038/s41598-020-77198-5.

Correspondence and requests for materials should be addressed to Z.D.-K.

Reprints and permissions information is available at www.nature.com/reprints.

Publisher's note Springer Nature remains neutral with regard to jurisdictional claims in published maps and institutional affiliations.

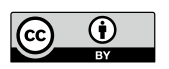

Open Access This article is licensed under a Creative Commons Attribution 4.0 International License, which permits use, sharing, adaptation, distribution and reproduction in any medium or format, as long as you give appropriate credit to the original author(s) and the source, provide a link to the Creative Commons licence, and indicate if changes were made. The images or other third party material in this article are included in the article's Creative Commons licence, unless indicated otherwise in a credit line to the material. If material is not included in the article's Creative Commons licence and your intended use is not permitted by statutory regulation or exceeds the permitted use, you will need to obtain permission directly from the copyright holder. To view a copy of this licence, visit http://creativecommons.org/licenses/by/4.0/.

(C) The Author(s) 2020 